\title{
Using information citizenship to drive knowledge management culture
}

\author{
Melanie Sutton \\ Knowledge Officer \\ The IQ Business Group \\ msutton@iqgroup.net
}

\section{Introduction}

Our research and investigations in this column have helped us to define that information citizenship refers to our responsibilities, duties and appropriate conduct and behaviour for inclusion and participation in the knowledge economy.

Our behaviour towards information, our knowledge worker attributes and our commitment to lifelong learning and development are key components to becoming model information citizens.

We have also discovered that by understanding our generational profiles and subsequent learning styles and information behaviour we can develop inter-generational information citizenship behaviour, where all members can fully participate and reap the benefits of the information economy.

Whereas information citizenship is targeted at a personal level, we cannot help but consider how this behaviour can be translated into a driver for creating an effective knowledge management culture.

\section{Strategic importance of knowledge management for organizations of the future}

Knowledge management is not an abstract proposition for the future. It is a vital aspect of world class management in today's business environment. Knowledge helps organizations to organize, its management helps managers manage. The failure to manage knowledge can be expensive.

The capacity to construct new knowledge is seen by many to be particularly important for organizational survival. The capacity to learn is seen by many as the key organizational capacity necessary for survival in this century, and being able to learn faster than the rate of change is seen as vitally important. Organizations must be adaptive rather than tightly controlled.

While specialists are clearly critical to the success of knowledge management, even more important are the activities and attitudes of those who are paid to do something other than manage knowledge. Planning managers, business analysts, design and manufacturing engineers, marketing professionals and even secretaries and clerks are the most important managers of knowledge. They all need to create, share, search out and use knowledge in their 
daily routines. In this sense knowledge management must be part of everyone's job.

\section{Knowledge management culture}

Culture, mainly shaped by people, is a basic building block to knowledge management and is a powerful force. It must be considered when introducing a knowledge management programme because it affects how the enterprise accepts and fosters that programme. The ultimate success of knowledge management depends on a supportive culture. If knowledge management must be an integrated aspect of how work gets done in an enterprise, it must become an integrated aspect of the culture (Ndlela and Du Toit 2000).

Early knowledge management initiatives tended to be large, corporate wide and with complex justifications. Some achieved a degree of productive change in the organization's exploitation of information, many failed with massive costs, and some fell short of huge expectations by small margins but were closed because they had not changed the organizational 'knowledge culture'.

Knowledge management involves deep-rooted behavioural and attitudinal changes. Genuine knowledge management implies higher degrees of empowerment and well-informed empowered individuals. People and organizational culture are the most important dimension of (or most serious barrier to) a successful knowledge management implementation.

Organizations typically apply new programmes to a culture, that is, the programmes are introduced and added to the existing culture instead of being integrated into it. In other words, the culture is neither examined nor altered as to its fit. The beliefs, values and systems, policies and management styles in place within the culture will work against the knowledge management overlay (Ndlela and Du Toit 2000).

Employees contribute to culture by helping to shape the values the enterprise embodies. Employees also play a role in influencing corporate culture by forming sub-cultures. Subcultures are units within an enterprise that are based on the shared values, norms and beliefs of their members. Because sub-cultures influence their member's behaviour, they are important factors for business leaders to consider (Ndlela and Du Toit 2000).

Human beings are central to knowledge management practice. It is people who have knowledge, who require knowledge and who can exploit knowledge for competitive advantage. Emphasis is on intellectual capital. Knowledge must genuinely become part of our culture, or rather a culture of knowledge must be developed (De Beer).

\section{Crafting the synergy between information citizenship and knowledge culture}

Organizations can take advantage of employees' personal information citizenship behaviour to drive knowledge culture in the organization. However, organizations must be aware that they have an accountability to put the correct infrastructures in place and to employ custodians and managers of knowledge who can drive and capitalize on the individual information skill and behaviour and build the knowledge culture.

Organizations should take into consideration the following factors that will influence the success of this synergy:

- Employees participate in knowledge management initiatives, belonging to communities of practice, yet return to a non-supportive culture within their own division/team. Because of the lack of results, the enterprise rationalizes that knowledge management does not work (Ndlela and Du Toit 2000) 
- Measurement is all about people, look at the 'what is in it for me' factor for all stakeholders, including the individual, enterprise and customer. Return on investment (ROI) is fastest when new processes allow users to stay within their 'comfort zone' (Hanley 2003)

- Very often, secrecy in business is an attempt to hide ignorance, not to hide knowledge. A negative attitude to sharing information might be built into the corporate culture right from the top. This has to be changed first, if initiatives for knowledge networking are to have any chance of success.

- Getting individuals to share is much more a matter of giving them easy-to-use tools than retraining them psychologically. To share openly, individuals need tools and top level proactive assistance and approval. Motivation will arrive via feedback and automated feedback can help complete the knowledge loop.

- Knowledge management is part of everyone's job. Of course it will usually take the efforts of some full-time knowledge staff to make knowledge management a pervasive phenomenon. However important knowledge is, it is a meaningless entity unless there are people, that is, knowledge experts and knowledge generators and, finally, fully qualified knowledge workers, managers, configurers and enablers (De Beer). Information professionals have a key role to play in the development of knowledge management - a discipline and profession geared to increasing our understanding of and ability to control knowledge resources available to us (Ford 1991 cited in Field).

\section{Conclusion}

Information citizenship is a personal choice that individuals make to thrive in the knowledge economy. Knowledge culture is the cornerstone of any knowledge management initiatives. By taking advantage of an employee's personal information citizenship beliefs and behaviours, within the context of building an organization knowledge culture, means that organizations have a sturdy foundation to work from, can easily identify cultural factors that require a hands-on approach and capitalize on aspects that are already supporting the culture.

Information citizenship is a powerful means to create a sustainable knowledge culture.

\section{References}

De Beer, C.S. 2005. The challenge to the contemporary knowledge worker: the troubadour of knowledge. [Online]. Available WWW: http://www.dev.unisa.ac.za/contents/faculties/ humanities/docs/faniedebeer.pdf (Accessed October 2005).

Field, M. 1999. Our competitive future: building the knowledge driven economy. [Online]. Available: WWW : http://www.la-hq.org.uk/directory/prof_issues/ocf.html (Accessed October 2005).

Hanley, S. 2003. Show me the money: a practical framework for KM metrics. [Online]. Available WWW: http://www.kmworld.com/kmw03/presentations/Hanley.pdf (Accessed October 2005).

Ndela, L.T. and Du Toit, A.S.A. 2000. Corporate culture as a foundation for successful knowledge management. [Online]. Available WWW: http://general.rau.ac.za/infosci/raujournal/vol1.nr4.01_03_2000/peer2.asp (Accessed October 2005).

River Path Associates. 1998. Shared knowledge, shared urgency. [Online]. Available WWW: http://www.riverpath.com/library/documents/shared knowledge_report.htm (Accessed October 2005). 
The Library Association. 1999. Knowledge diffusion and sense making as key knowledge processes. [Online.] Available WWW: http://

www.leadershipcentre.co.za/docs/knowledge.pdf (Accessed October 2005).

\section{About the author}

Melanie Sutton (BA, Postgraduate Diploma in Information Management) is a Senior Principal Consultant in the Enterprise Content Management Discipline and a member of Intellectual Property Forum at The IQ Business Group, South Africa.

\section{Disclaimer}

Articles published in SAJIM are the opinions of the authors and do not necessarily reflect the opinion of the Editor, Board, Publisher, Webmaster or the Rand Afrikaans University. The user hereby waives any claim he/she/they may have or acquire against the publisher, its suppliers, licensees and sub licensees and indemnifies all said persons from any claims, lawsuits, proceedings, costs, special, incidental, consequential or indirect damages, including damages for loss of profits, loss of business or downtime arising out of or relating to the user's use of the Website. 
ISSN 1560-683X

Published by InterWord Communications for Department of Information and Knowledge Management, University of Johannesburg 